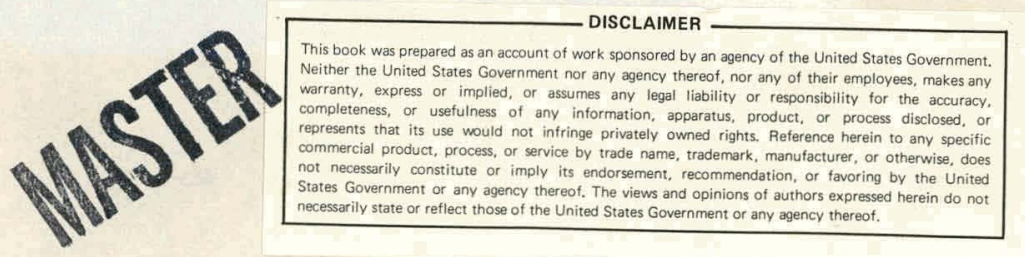

DOE/ER/01545-281

\title{
MEASUREMENT OF CHARMED PARTICLE LIFETIMES
}

\author{
N.W. Reay \\ Ohio State University, Columbus, Ohio
}

ABSTRACT

This talk briefly reviews recent measurements of charmed particle lifecimes, then presents in detail the lifetime measurements of Fermilab Experiment 531 .

\section{INTRODUCTION}

I was really impressed by the preceding talk of Professor Carnegie, in which results of many experiments were synthesized to give a coherent picture of meson spectroscopy. The reason that this could be done is that all experiments relied on conventional techniques, and therefore could be trusted. Today, I want to talk to you about the charmed particle lifetime business. People in this business have been known to use emulsions and even cosmic rays, so all experiments have a unifying feature -- no one believes them. For example, when Professor Niu of Nagoya ${ }^{1}$ discovered charmed particles in a cosmic ray emulsion exposure, very little excitement was created in the high energy physics community. In fact, the field lay dormant until the discovery of the $\mathrm{J}-\Psi$.

of course, there is some justification for this state of affairs. The GIM coupling of electroweak theory to hadrons made it possible to predict charmed particle lifetimes, and predictions ranged within less than an order of magnitude about $10^{-13}$ seconds. However, as recently as at the 1978 Tokyo High Energy Conference, experimental results were divided into two camps, one with lifetimes $10^{-13}$ seconds or ionger and another with lifetimes $10^{-14}$ seconds or shorter. The latter was in flat contradiction to the above mentioned theory.

\section{RECENT EXPERIMENTAL RESULTS}

In the past year, results trom several L'EN and Fermilab exper Iments have supported longer lifetimes. CERN experiment WA 17 has published five decays, one of which has been mass fit. ${ }^{2}$ CERN experiment WA 4 has found a decay generated in a photon interaction. 3 Two bubole, chamber experiments at Fermilab recently reported results at Bergen. ${ }^{4,5}$ Experiment 546 has four visible decays and experiment 53 has one visible charged decay. These experiments suffer from obvious deficiencies in seeing short lifetimes, but have the distinct advantage that they have a known number of decays. For example, experiment 53 has $250 \mu-e$ di-lepton events, most of which presumably contain the decay of a charmed particle. If charmed lifetimes were long, they would have found 250 visible decays. Professor Baltay has furnished me the graph of expected visible decays versus lifetime show in Figure 1; his result certainly is consistent with a charged lifetine of roughly $5 \times 10^{-13}$ seconds.

Now that ballpark numbers exist for charmed particle lifetimes, we wust determine lifetimes and branching ratios for each of the ISSN:0094-243X/80/590077-13\$1.50 Copyright 1980 American Institute of Physics 


\section{DISCLAIMER}

This report was prepared as an account of work sponsored by an agency of the United States Government. Neither the United States Government nor any agency Thereof, nor any of their employees, makes any warranty, express or implied, or assumes any legal liability or responsibility for the accuracy, completeness, or usefulness of any information, apparatus, product, or process disclosed, or represents that its use would not infringe privately owned rights. Reference herein to any specific commercial product, process, or service by trade name, trademark, manufacturer, or otherwise does not necessarily constitute or imply its endorsement, recommendation, or favoring by the United States Government or any agency thereof. The views and opinions of authors expressed herein do not necessarily state or reflect those of the United States Government or any agency thereof. 


\section{DISCLAIMER}

Portions of this document may be illegible in electronic image products. Images are produced from the best available original document. 


\section{The following pages are an exact representation of what is in the original document folder.}




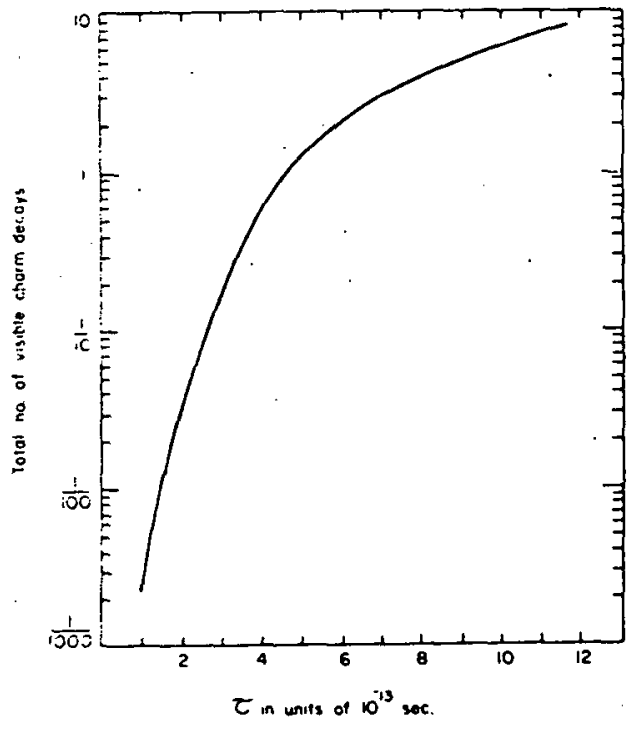

Figure 1: Expected number of $v$ isible decays given as a function of lifetime for Fermilab Exp.53. different types of lightest charmed particles. It is even concelvable that the anomalously short measured lifetimes were the result of an unexpectedly broad spectrum of lifetime values. Three Fermilab experiments deslgned to answer more detalled questions completed data taking in February, 1979. Though they all exposed hybrid emulsion. spectrometers to the same single horn wide band neutrino beam, each was quite different in character.

Experiment 553, shown in Figure 2, used thin emulsion modules, holey spark chambers for event location, a magnetic spectrometer for momentum analysis and a flash tube calorimeter for detection of electromagnetic and hadronic showers.

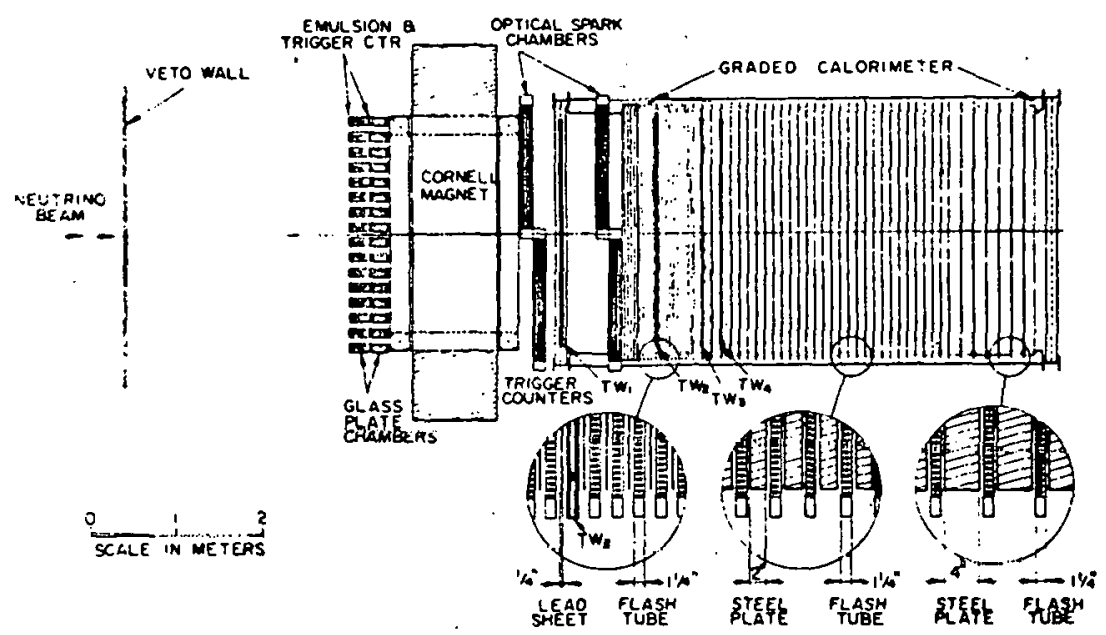

Figure 2: A layout for Fermilab Experiment 553.

The holey spark chamber is conceptually quite clever. The chambers consist of glass plates coated with a metallic layer so thin that sparks burn holes in the coating. Contact prints are then made of fired plates, enabling 50 micron accuracy in location of track coordinates. Professor Hand las informed me that on the basis of $1 / 3$ to $1 / 2$ of their total data sample they have located 25 neutrino interactions and have found one "kink" and one multiprong decay candidate. As neither has been mass $f 1 t$, proper decay times are not yet available. 
Fermilab experiment 564 placed Russian emulsions inside the 15foot bubble chamber at cold temperature, so that the bubble chamber itself became the downstream detector. Professor Voyvodic has informed me that based on a small fraction of their expected data base, they have located about two dozen neutrino interactions and have discovered two three prong charged charmed particle decays. ${ }^{6}$. The proper time and particle ldentification are not yet avallable.

FERMILAB EXPERIMENT 531

\section{A. Counter System}

Now, I wish to exercise the time honored perogative of rapporteurs everywhere by. spending the remainder of the time discussing the experiment on which I work -- Fermilab experiment 531. The apparatus shown in Figure 3 was constructed and operated by a large collabora-

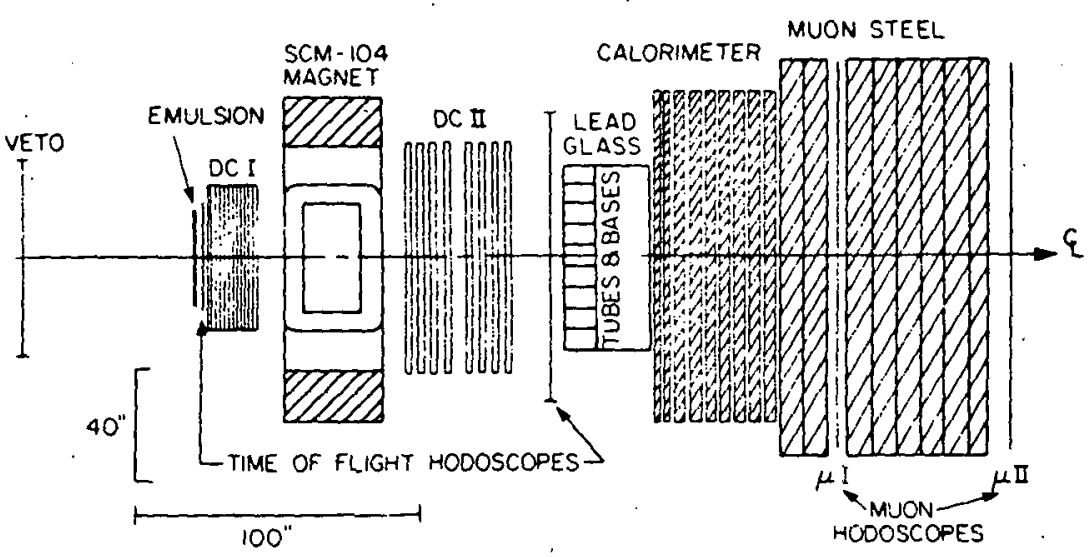

Figure 3: A layout for Fermilab Experiment 553.

tion of Canadian, Japanese, Korean and Unj.ted States scientists. 7 simple neutrino trigger required only that no charged particle be incident and that two or more charged particles exit the emulsion and pass through the magnet. Charged and neutral current events were acrepted equally. A magnet surrounded by drift chambers provided momentum analysis. and alded In linding events within the emulsion. A time-of-flight system separated pions and kaons to $2 \frac{1}{2} \mathrm{GeV}$, and protons to $5 \mathrm{GeV}$. A wall of lead glass detectors was used to identify electromagnet1c showers and muons were identified by passage through 1.6 and/or $3 \mathrm{GeV}$ equivalent of steel. Non-electromagnet lc hadruili energy was recorded in a conventional iron plate calorimeter. Information on resolution of spectromecer elemento is summarized in Table I.

At this point, let me emphasize the philosophy of our counter system. A hybrid enulsion effort must be viewed as a complete counter effort in addition to the obvious emulsion technology. Many such experiments have suffered grievously because the counters were viewed 36 a necessary but minimal adjunct. Be assured that within statist - 


\section{Quantity Measured}

Drift Chamber Posttion Resolution

Charged Particle Momenta for

Tracks passing through magnet

Tracks analyzed only by fringe field

Gamma Ray Energy

Gamma Ray Position

Time-Of-Flight

Calorineter

\section{Error $(\sigma)$}

120 microns

$\frac{\delta P}{P}=.013+.005 P$

$\frac{\delta \mathrm{P}}{\mathrm{P}} \approx 0.3 \mathrm{P}$

$\frac{\delta E}{E}=\frac{0.3}{\sqrt{E(G e V)}}$

$5 \mathrm{~cm}$

120 picoseconds

$\frac{\delta \mathrm{F}}{\mathrm{E}}=\frac{1.0}{\sqrt{\mathrm{E}(\mathrm{GeV})}}$

cal 1 initations, E-531 exhibits features typical of most bulk neutrino experiments. Using counter data only, the distribution in $v i s i b l e ~ e n e r g y$ of events has been calculated and is displayed in Figure 4. The visible energy was calculated by suming muon energy

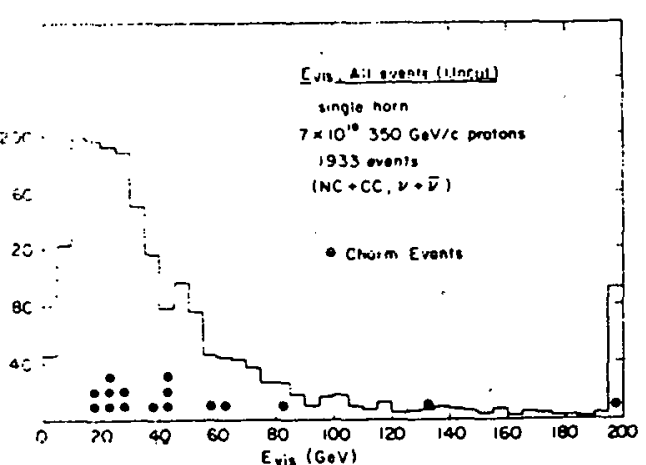

Figure 4: Energy distribution of events for E-531. The asterisks indicate individual events which have charn decays. with lead glass and calorimeter energies. The distribution is typical of the horn heam, and events with charm show no ștrong differentiation in shape. A subset selected to have visible energy greater than 10 $\mathrm{GeV}$ have been assigned to neutrino or anti-neutrino distributions by the sign of the leading muon. The $x$ and $y$ distributions shown in Figures 5 and 6 exhibit the expected features for charged current interactions. The raw neutrino distributions are flat in $y$ and agree in $x$ with the exhibited $F_{2}(x)$ shape taken from SLAC inelastic e-D scattering data.

The distribution of events containing charm is similar to the overall event distributions. The anti-neutrino distribut luns as expccted are peaked at small $x$ and $y$, and there is a hint of the expected flat distribution in $y$ of charmed events. 


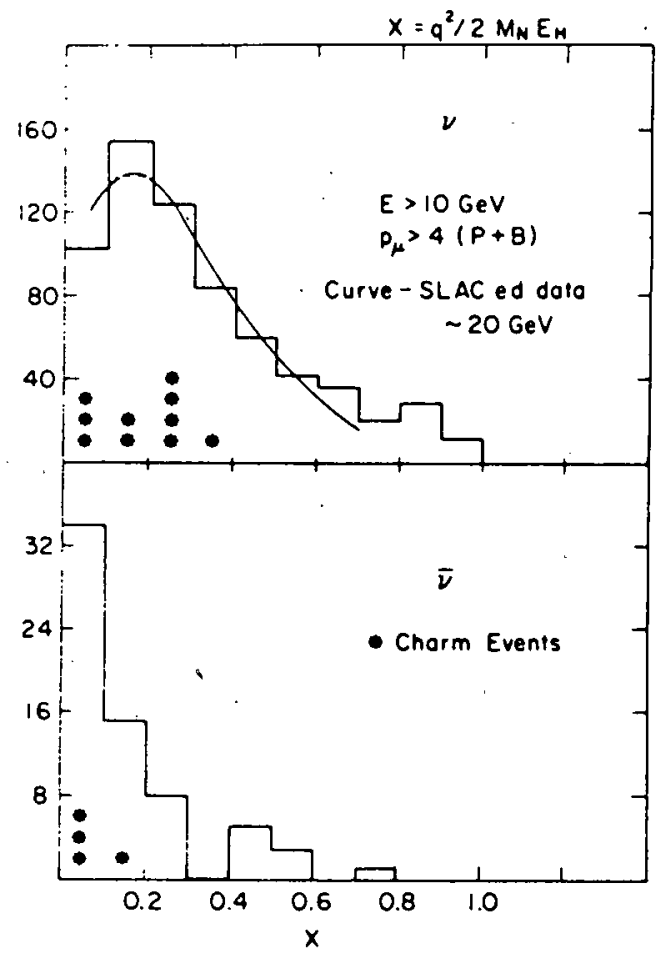

Figure 5: $\mathrm{X}$ distribution of charged current events for E-531.

Figure 6: Y distribution of charged current events for E-531.

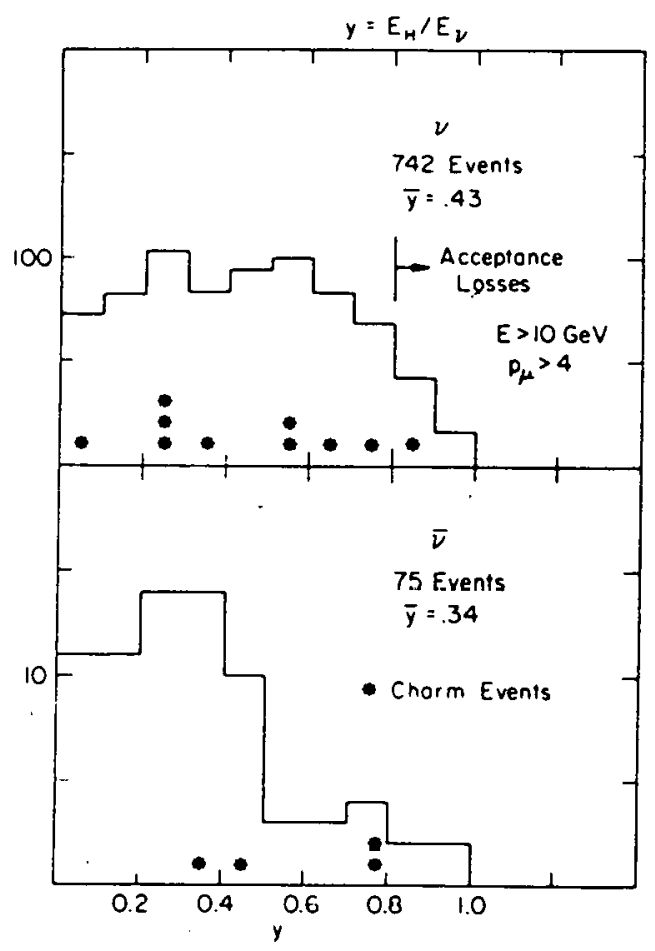




\section{B. Emulsion System}

The emulsion target consisted of over three thousand sheets of exulsion, roughly half of which had 300 micron layers of emulsion coated on each side of a 70 micron plastic backing and which were mounted normally to the neutrino beam. One module of this type is exhibited in Figure 7. The remainder were 600 micron pure emulsion pellicles mounted edge-on to the beam. The latter were scanned for events by searching a sinall volume surrounding the vertex location inferred from intersection of drift chamber tracks. The normally mounted emulsion was scanned using the changeable sheet setup shown in Figure 7. An 800 micron sheet of lucite coated on both sides with a thin layer of emulsion was placed immediately downstream of the emulsion stack. This sheet was located with respect to the emulston modules by means of $X$-ray sources residing in the posts on which all emulsion modules were mounted. As there were almost 150 posts, changeable sheets were liberally speckled with precisely located blackened spots. By changing this sheet many times during the experiment, muon and other background were kept sufficiently low that individual tracks could.be found from drift chamber information using computer-controlled semiautomatic scanning technlques. Once an individual track from an event was found, highly precise emulston techniques could be employed to extrapolate tracks back to the literaction vertex. Such a technique is highly efficient because it does not rely on the existence of a large number of black tracks from nuclear breakup as does the volume scan method. Recent developments indicate that the scanback technique will be applicable as well to emulsions mounted edge on.

Presently, we have 1700 events predicted via computer fits to drift chamber data. By comparing efficiencles of two separate fitting programs, we have determined that a final analysis should locate 2200 events; the final analysis should be avallable shortly. Scanning of the expected 2200 events is about $40 \%$ complete, resulting in the event finding efficlency exhibited in Table II.

\section{Analysis}

To date, we have located 20 multiprong charm decays, and have an additional dozen "kinks" in which a single track undergoes a large angle instantaneous change in direction without evidence of nuclear breakup. Eleven of the multiprong decays have unique identification, and three more are ambiguous between assignment as $D$ or $F$ mesons.

In the following, decay hypotheses have been shown and particles 


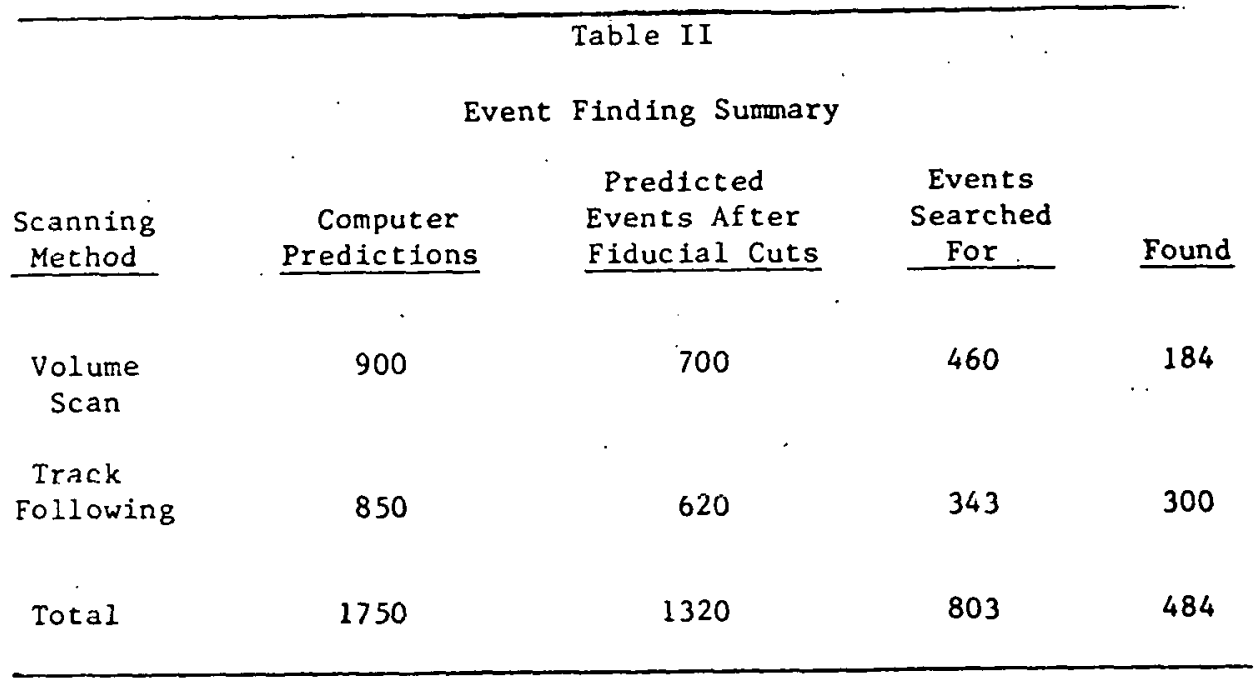

Table III

$\Lambda_{c}^{+}$Baryon Fits

\begin{tabular}{|c|c|c|c|c|}
\hline $\begin{array}{l}\text { Decay Length } \\
\text { (Microns) }\end{array}$ & Hypothes is & $\begin{array}{c}\mathrm{P} \\
(\mathrm{GeV} / \mathrm{c}) \\
\end{array}$ & $\begin{array}{l}\text { Mass } \\
(\mathrm{MeV}) \\
\end{array}$ & $\begin{array}{l}\text { Decay Time } \\
\times 10^{-13} \\
\text { Seconds } \\
\end{array}$ \\
\hline 27 & $\Lambda c^{-} \underline{P} \underline{\pi}^{+} \pi^{-}\left(K^{0}\right)$ & $\begin{array}{l}2.4 \\
1.8\end{array}$ & $>2070$ & $\begin{array}{l}0.8 \\
0.4\end{array}$ \\
\hline 15 & $\Lambda c^{-} \mathrm{K}^{-} \underline{\mathrm{P}} \underline{\pi}^{+}\left(\pi^{0}\right)$ & $\begin{array}{l}1.9 \\
2.7\end{array}$ & $>2170$ & $\begin{array}{l}0.6 \\
0.4\end{array}$ \\
\hline 40 & $\Lambda c^{+} \underline{\Lambda}^{0} \underline{\pi}^{+} \underline{\pi}^{-} \pi^{+}$ & 5.3 & $\begin{array}{r}2220 \\
\pm 90\end{array}$ & 0.6 \\
\hline
\end{tabular}

which have been identif ted as well as momentum analyzed are underlined. Unseen particles added to balance momentum transverse to the direction of the parent particle are indicated in brackets. When all particles are momentum-analyzed a two constraint $f$ t is possible; when a.particle is missing the resulting zero constraint fit in general has two solutions. Frequently, one of these solutions may be eliminated, as in cases where the mass solution is at a minimum or when in conjunction with another particle a better higher mass meson (such as $D^{\star}$ or $F^{\star}$ ) may be formed. Decay lengrhs are given in microne, $P$ is the momentum determined for the parent charmed particle and proper decay times are given in units of $10^{-13}$ seconds. Table III 
contains the three $\Lambda_{c}^{+}$events, Table IV the four $D^{0}$ events and Table $V$ the charged $D$ and $F$ events, including the three events which cannot be uniquely assigned.

The preliminary mean life for the $\Lambda_{c}^{+}$baryon obtalned by averaging the individual pruper decay times is

$$
\langle\gamma\rangle=0.6 \times 10^{-13} \text { seconds }
$$

\begin{tabular}{|c|c|c|c|c|}
\hline & Table & IV. & & $\cdot$ \\
\hline $\begin{array}{l}\text { Decay Length } \\
\text { (Microns) }\end{array}$ & Hypothesis & $\begin{array}{c}\mathrm{P} \\
(\mathrm{GeV} / \mathrm{c}) \\
\end{array}$ & $\begin{array}{l}\text { Mass } \\
(\mathrm{MeV})\end{array}$ & $\begin{array}{c}\text { Decay Time } \\
\times 10^{-13} \\
\text { Seconds } \\
\end{array}$ \\
\hline 34 & $\overline{D^{0}} \rightarrow \pi^{+} \pi^{+} \underline{\pi}^{-} \pi^{-}\left(\pi^{0}\right)$ & 10 & $>1880$ & 0.21 \\
\hline 40 & $D^{0} \rightarrow K^{-} \pi^{-} \underline{\pi}^{+} \underline{\pi}^{+} \underline{\pi}^{0}$ & 15 & $\begin{array}{r}1830 \\
\pm 40\end{array}$ & 0.16 \\
\hline 74 & $D^{0} \rightarrow \pi^{+} \pi^{-}\left(K_{L}{ }^{0}\right)$ & 12.4 & $\begin{array}{l}1870 \\
\pm 180\end{array}$ & 1.9 \\
\hline 210 & $D^{0} \rightarrow K^{+} \pi^{-}\left(\pi^{0}\right)$ & $\begin{array}{l}6.7 \\
8.3\end{array}$ & & $\begin{array}{l}1.9 \\
1.6\end{array}$ \\
\hline
\end{tabular}

For the pvent with the missing $k^{0}$ the lower momentum solution was chosen because the combined mass of the $D^{0}$ and another $\pi^{+}$from the event is closer to the $D^{\star}$ mass. The preliminary mean life for the $D^{0}$ obtained by averaging the proper decay times of these events is

$$
\langle r\rangle=0.7 \times 10^{-13} \text { seconds }
$$

In addition to volume scanning downstream of each neutrino interaction for neutral decays, a variation of the track scanback rechuique wae applied to search for decays undiscovered by the first technique. In this variation, tracks found by the drift chambers which had slopes difierent from those measured in the emulsion at the primary vertex were identifled in the changeable sheet and traced back into the emulsion. In 150 events treated in this manner, many nuclear interactions and electron-positron pairs were discovered, but no new charm decays were identifled. This fact coupled with the short desay lengths of found events supports a high efficlency for finding $D^{0}$ decays: 
Table V

$F$ and Charged D Meson Fits

\begin{tabular}{|c|c|c|c|c|}
\hline $\begin{array}{c}\text { Decay Length } \\
\text { (Yicrons) }\end{array}$ & Hypotheses & $\begin{array}{c}P \\
(\mathrm{GeV} / \mathrm{c}) \\
\end{array}$ & $\begin{array}{l}\text { Mass } \\
(\mathrm{MeV})\end{array}$ & $\begin{array}{r}\text { Decay Time } x \\
10^{-13} \text { seconds } \\
\end{array}$ \\
\hline . & $\underline{F}$ Mesons & & & \\
\hline 670 & $F^{-}+\underline{\pi}^{+} \underline{\pi}^{-} \pi^{-} \underline{I}^{0}$ & 12.8 & $2068 \pm 60$ & 3.6 \\
\hline \multirow[t]{2}{*}{130} & $\mathrm{~F}^{+} \rightarrow \mathrm{K}^{+} \underline{\pi}^{+} \underline{\pi}^{-}\left(\mathrm{K}^{0}\right)$ & 10.4 & $\sim 2130$ & 0.8 \\
\hline & Charged D Mesons & & & \\
\hline 1802 & $\mathrm{D}^{+} \rightarrow \mathrm{K}^{+} \mathrm{K}^{-} \underline{\pi}^{+} \underline{\pi}^{0}$ & 17.8 & $1851 \pm 30$ & 6.4 \\
\hline \multirow[t]{2}{*}{2145} & $D^{+} \rightarrow K^{-} \pi^{+} \mu^{+}(11)$ & $\begin{array}{l}12.8 \\
24.8\end{array}$ & & $\begin{array}{r}10.4 \\
5.4\end{array}$ \\
\hline & Ambiguous Events & & & \\
\hline \multirow[t]{2}{*}{530} & $\begin{array}{c}\mathrm{F}^{+} \rightarrow \mathrm{K}^{-} \mathrm{K}^{+} \pi^{+} \underline{\pi}^{0} \\
\text { (Favored) }\end{array}$ & 34 & $2057 \pm 60$ & 1.1 \\
\hline & $D^{+}+K^{-} \pi^{+} \pi^{+} \underline{\pi}^{0}$ & 34 & $1964 \pm 60$ & 1.0 \\
\hline \multirow[t]{2}{*}{2307} & 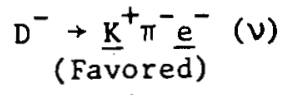 & $\begin{array}{r}6.7 \\
10.5\end{array}$ & & $\begin{array}{l}21.4 \\
13.7\end{array}$ \\
\hline & $\mathrm{F}^{-} \rightarrow \underline{K}^{+} \mathrm{K}^{-} \underline{e}^{-}(\nu)$ & $\begin{array}{l}6.9 \\
7.5\end{array}$ & & $\begin{array}{l}22.7 \\
20.9\end{array}$ \\
\hline \multirow[t]{2}{*}{457} & $\mathrm{D}^{+} \rightarrow \mathrm{K}^{-} \pi^{+} \underline{\pi}^{+} \underline{\pi}^{0}$ & 10 & $1835 \pm 50$ & 2.8 \\
\hline & $\mathrm{F}^{+} \rightarrow \mathrm{K}^{-} \mathrm{K}^{+} \underline{\pi}^{+} \underline{\pi}^{0}$ & 10 & $20.12 \pm 49$ & 3.1 \\
\hline
\end{tabular}

If only uniquely determined decays are used, two charged $D$ and two $F$ meson events give

$$
\begin{aligned}
& \left\langle r \quad>=7 \times 10^{-13}\right. \text { seconds } \\
& \left\langle r>=2 \times 10^{-13}\right. \text {. seconds }
\end{aligned}
$$

After assigning tho additional decays to their one sigma favored particle types and weighting the ambiguous event by 0.5 for each of its twofold amblguous solutions, the following lifetimea may be obtained.

$$
\begin{aligned}
& <T>=9 \times 10^{-13} \text { seconds } \\
& <T>=1.8 \times 10^{-13} \text { seconds }
\end{aligned}
$$

The ratio of $D^{0}$ to charged $D$ lifetimes is then

$$
\frac{\left\langle T_{D}^{0}\right\rangle}{\left\langle T_{D^{ \pm}}{ }^{0}\right\rangle}=0.08 \pm 0.06
$$


(though with the small statistics involved, a \pm error is inferior to values determined by maximum 11kelihood). Evidence that all four $D^{0}$ decays are non-leptonic, whereas the three decays favoring the charged D Identification were semi-leptonic or Cabibbo-unfavored non-leptonic also is supportive of the large difference in lifetimes.

We also studying an increasingly interesting amount of dymamical information concerning these decays. All $\Lambda_{c}^{+}$baryons were produced slowly in the laboratory, as might be expected if their production is assumed to be target-11ke. Many, if not most of the $D$ and $F$ mesons appear to come from strong decays of $D^{\star}$ and $F^{\star}$ higher mass states, and about half of the charmed particles appear to contain most of the visible hadronic energy. We should have more to say about these points in the near future.

Scanning should be complete by next sumer, obtaining roughly 50 multiprong and an uncertain number of analyzed single track decays. At that time we are approved to run again with improvements both to backgrounds and equipment, and expect to flind even more decays. I could bore you with Iists of Improvements and dreams for the future, but the proper time to discuss this sort of thing is after running and not before. Let me close instead by discussing two "zoo" events which are as yet incompletely understood.
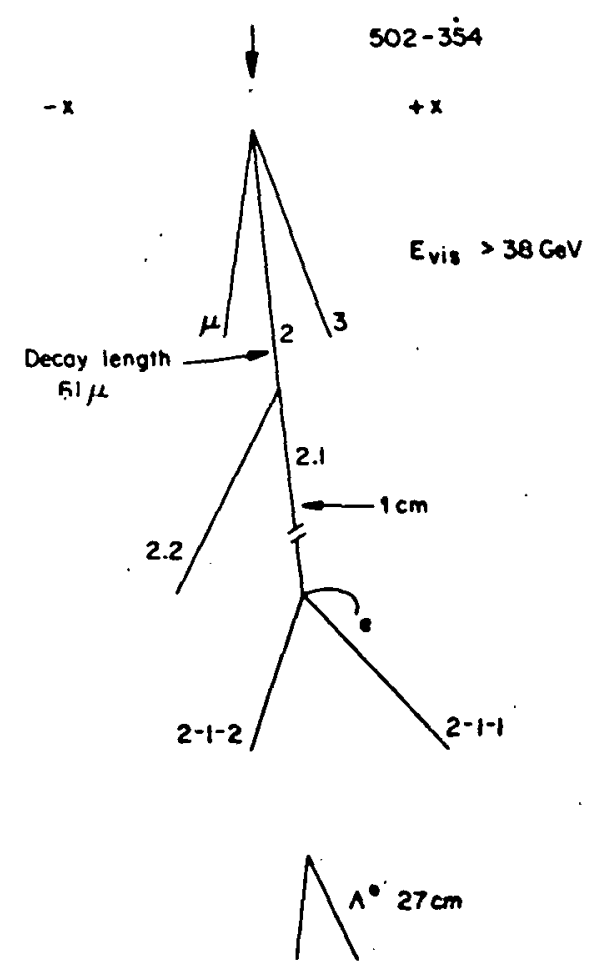

Figure 8: Decay of doubly charged particle, see text for a description.

\section{Two Unusual Events}

We have found the charged two decay track 1llustrated in Figure 8. Three tracks emerge from a neutrino interaction, two of these are minimum Ionizing while the third has been measured by two methods to have an iontzation $4.0 \pm 0.5$ times more dense than nearby minimum lonizing charged tracks plus at least one neutral particle. Multiple scattering measurements in tho emulsion have ylelded momentum values of $\mathrm{P}_{2-1} \overline{>} 3.0 \mathrm{GeV} / \mathrm{c}$ and $P_{2-2}=0.6 \pm 0.15 \mathrm{GeV} / \mathrm{c}$. 'The former track travels about $1 \mathrm{~cm}$ in the emulsion before interacting without evidence of nuclear breakup (or decaying) to give two minimum lonlzing tracks and an electron of momentum $60 \pm 10 \mathrm{KeV} / \mathrm{c}$. Unfortunately, this event occurred when the spectrometer magnet was off due to a power supply fallure and no momentum measurements could be performed by the magnet ic spectrometer. A "vee" materlalized downstream of the emulston and was identified by time-of-flight measurements to be a 
lambda hyperon. An electron-positron pair also is observed in the emulsion and has been connected to spectrometer tracks which show that it is in time with and therefore assoclated with this event. We are still working and though we are strongly tempted to speculate on the existence of a weakly decaying charge two baryon, we w11l rake no claims at this time.

The second unusual event, shown in Figure 9 is one which contains three electrons. The table given as an insert in Figure 9 tells the story. Tracks 1 and 2-2 were clearly identifled as electrons, as the momentum measured by the magnetic spectrometer equalled the energy measured by the lead gless blocks struck by these tracks. The identification of track 3 is not so clear, as the energy measured by the lead glass is only $70 \%$ of that measured by the magnetic spectrometer. This event could be quite exciting, but we are waiting for emulsion measurement on the two tracks found in the emulsion but not ipicked up by our drift chambers. Visions of many exciting possibilities dance in our heads, but if these two tracks turn out to be electrons the event could be as ordinary as a gamna-induced shower. It is safe to say that we do not yet uncerstand this event, and $I$ am hopeful that after the end of the talk one of you will leap up with an explanation. So without further ado let me close by thaniking you for this invitation to talk in the beautiful city of Montreal.

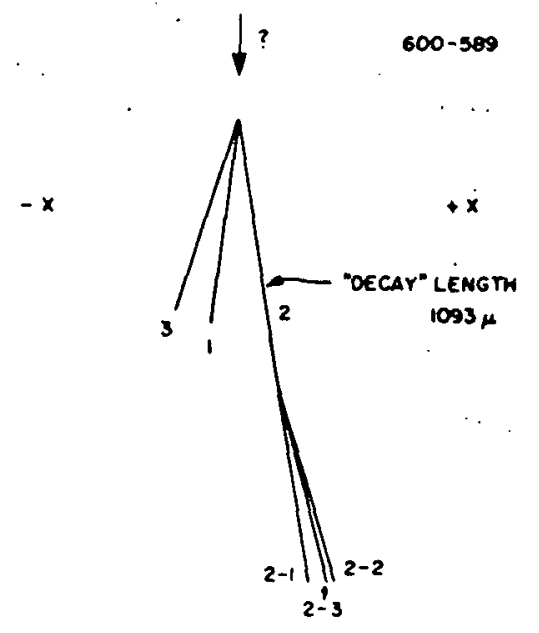

\begin{tabular}{|c|c|c|c|c|}
\hline TRACK & $\frac{d x}{d z}$ & $\frac{d y}{d z}$ & $p$ & 1.0 \\
\hline 1 & -.059 & -.057 & -8.0 & $\cdots$ \\
\hline 3 & -.157 & -.054 & -3.7 & -1 \\
\hline 2 & .073 & .027 & & \\
\hline $2-1$ & .075 & 027 & & \\
\hline $2-2$ & .137 & .023 & 36 & 0 \\
\hline $2-3$ & .117 & -.091 & & \\
\hline
\end{tabular}

Figure 9: Multi-electron event, see text for a description.

We wish to acknowledge the financial support of the U.S.D.O.E., the Canadian N.S.E.R.C., the Japanese Mintstry of Education and other private contributors, and the Korean Science Foundation. We thank the many memoers of the Fermilab staff and the technical personnel in our universities for their contributions to our experiment. 


\section{DISCUSSION}

A.Abashian, National Sclence Foundation:

of the neutrino events in which a charmed particle is produced, how many are charged current(outgoing $\mu$ ) and how many are neutral current (outgoing neutrino)?

\section{N.W.Reay:}

Based on our Monte Carlo, we have a $35-40 \%$ rat 10 of neutral to charged currents, which is a little high. On an event by event basis it is difficult to say whether an event is truly a neutral current event or appears to be so because the muon missed the detector. At least one of our charmed decay events has no tagged muon.

Isgen, University of Toronto:

I was concerned by your $F$ with a mass of around $2130 \mathrm{MeV}$. You mentioned that the event was difficult; are the problems sufficlent to make the mass consistent with the DESY value of about $230 \mathrm{MeV}$ ?

Reay:

This event was tough to measure in the emulsion; re-measuremerits gave considerably different values. I would say that for this event the minimum mass in this $O C$ fit has a large error and could be consistent with $2030 \mathrm{MeV}$.

\section{REFERENCES}

1. K.Niu et a1., Prog.Theor.Phys. 46, (1971) 1644.

2. R.Sever, et al., Contributed paper to neutrino 1979 Bergen Conference by the WA 17 Collaboration; Ankara-Brussels-CERNDublin-UC London-Open University-P isa-Roma-Torino.

3. A.Cont 1 et al., Contributed paper to the 1979 International Symposium on Lepton and Photon Interactions at High Energles, Bologna-CERN-Florence-Geneva-Mosrnw I.PI-Par 16 VI-SantanderValencia-Emulsion Collaboration and Bonn-CERit-EP Paris-GlasgowLandcaster-Manchester-Orsay-Paris VI-Parris VII-RutherforeSheffield Omega Collaboration. Also discussed in presentation by R.R1chard to this Conference.

4. D.Reeder, Invited talk at the 1979 International Symposium on Lepton and Photon Interactions At High Energles.

5. C.Baltay, private communication.

6. L. Voyvoufc, Invited talk at the 1979 International Symposium on Lepton and Photon Interactions At HIgh Energles, Fermilab-Conf79/80-Exp. 2050.00.

7. The names and institutions of the physiclsts who are currently working on this experiment are: N. Ushida, Aichi University of Education, Japan; T.Kondo, Fermi National Accelerator Laboratory; G.Fujioka, H.Fukushima, Y.Homma, O.Minakawa, J.Ortmoto, Y. Takayama, S.Tatsumi, Y.Tsuzuki, Kobe University, Japan; S.Y.Bahk, T.G.Chni, C.O.Kim, S.N.Kim, J.N.Park, Korea University; D.C. Bailey, S.Conetti, J.-R.Fisher, J.M.Trischuk, McGill University, Canada; H.Fuchi, K.Hochino, K.Ni.u, K.Niwa, Il.Shibuya, Y. 
Yanaglsawa, Nagoya Unlversity, Japan; S.M.Errede, M.J.Gutżw1ller, S.Kuramata, N.W.Reay, K.Re1bel, T.A.Romanowsk1, R.A.S1dwell, N.R. Stanton, Oh1o State University; K.Mor1yama, H.Sh1bata, Okayama Unlversity, Japan; T.Hara, O.Kusumoto, Y.Noguch1, Y.Takahash1, N.Teranaka, Osaka City University, Japan; J.-Y.Harno1s, C.D.J. Hébert, J.Hébert, B.McLeod, University of Ottawa, Canada; K.Okabe, J.Yokota, Sclence Education Institute of Osaka Prefecture, Japan; S.Tasaka, University of Tokyo, Japan; P.J.Dav1s, J.F.Martin, D.PItman, J.D.Prentice, P.Sinervo, T.-S.Yoon, University of Toronto, Canada; J.Kimura, Y.Maeda, Yokohama National Univers1ty, Japan. 